\title{
Competências em Educação: conceito e significado pedagógico
}

\author{
Isabel Simões Dias
}

\begin{abstract}
Resumo
O conceito de competência e a reflexão sobre o seu significado pedagógico assumem um papel de destaque na investigação em Educação a nível nacional e internacional. Este artigo procura enquadrar e definir o conceito de competência no contexto educativo, fazendo alusão à relação entre o construtivismo e uma abordagem por competências no processo de ensino/aprendizagem. Recorrendo a investigações multidisciplinares nacionais e internacionais, este estudo pretende constituir-se como um contributo para o entendimento do significado pedagógico do conceito de competências. Procura dados para reflectir acerca da intervenção educativa numa escola pluralista, multifacetada e em constante mutação. A educação é uma forma de intervenção no mundo, que solicita sujeito(s) aprendente(s), acção e contextos específicos. Esta mobilização dos recursos pessoais para uma resposta efectiva numa situação particular ocorre autonomamente quando se proporcionam oportunidades para a sua construção.
\end{abstract}

Palavras-chave: Competência, construtivismo, educação.

\section{Competencies in Education: concept and educational meaning}

\begin{abstract}
The concept of competence and the reflection about its educative meaning is an important issue in national and international education research. This essay pretends to frame and to define the concept of competence in educative field making a connection between constructivism and competence approach in teaching/learning process. Appealing to multidisciplinary national and international research, this study is a contribution for the understanding of the pedagogic meaning of the competence concept. It search data to reflect about educative intervention in a pluralist, multifaceted and in constant mutation school. Education is an intervention tool in a world that asks for learning students, action and specific contexts. This personal resource mobilization for an effective answer in a particular situation happens autonomously when opportunities are built for its construction.
\end{abstract}

Keywords: Competence, constructivism, education.

\section{Competencias en Educación: concepto y significado pedagógico}

\section{Resumen}

El concepto de competencia y la reflexión sobre su significado pedagógico asumen un papel de destaque en la investigación en Educación a nivel nacional e internacional. Este artículo procura encuadrar y definir el concepto de competencia en el contexto educativo refiriéndose a la relación entre el constructivismo y un abordaje por competencias en el proceso de enseñanza/aprendizaje. Al recurrir a investigaciones multidisciplinares nacionales e internacionales este estudio pretende constituirse como una contribución para el entendimiento del significado pedagógico del concepto de competencias. Busca datos para reflexionar sobre la intervención educativa en una escuela pluralista, multifacética y en constante mutación. La educación es una forma de intervención en el mundo que solicita sujeto(s) aprendentes, acción y contextos específicos. Esta movilización de recursos personales para una respuesta efectiva en una situación particular ocurre autónomamente cuando se proporcionan oportunidades para su construcción.

Palabras Clave: Competencia, constructivismo, educación. 


\section{Introdução}

O conceito de competência e a reflexão sobre o seu significado pedagógico assumem um papel de destaque na investigação em Educação a nível nacional e internacional (Comellas, 2000; Cruz, 2001; Gouveia, 2007; Perrenoud, 1999).

No âmbito escolar, a competência enfatiza a mobilização de recursos, conhecimentos ou saberes vivenciados. Manifesta-se na acção ajustada diante de situações complexas, imprevisíveis, mutáveis e sempre singulares (Boterf, 2003; Perrenoud, 2000, 2001, 2005).

Uma abordagem por competências enaltece o que o discente aprende por si, o aprender a aprender, a construção pessoal do saber através da interacção. Enaltece o conhecimento enquanto instrumento de aquisição de competências, elogia os conteúdos enquanto meios possibilitadores de desenvolvimento de competências. Valoriza o método pedagógico e a aprendizagem, superando a dicotomia teoria-prática e enraizando os valores educativos da escola do século XXI (Costa, 2004).

\section{Competência: enquadramento teórico}

O termo competência (do latim competentia, "proporção", "justa relação", significa aptidão, idoneidade, faculdade que a pessoa tem para apreciar ou resolver um assunto) terá surgido pela primeira vez na língua francesa, no século $X V$, designando a legitimidade e a autoridade das instituições (por exemplo, o tribunal) para tratar de determinados problemas. No século XVIII amplia-se o seu significado para o nível individual, designando a capacidade devida ao saber e à experiência.

No domínio da Psicologia este constructo aparece em trabalhos científicos pela primeira vez através de Noam Chomsky (nos anos 50 do século XX) no contexto da linguística, entendendo-se competência como a faculdade inata de falar e compreender uma língua (Perrenoud, 2005). Chomsky opõe competência a desempenho, entendendo a primeira como aquilo que o sujeito pode realizar idealmente devido ao seu potencial biológico, e o desempenho como o comportamento observável (Dolz \& Ollagnier, 2004).

A partir dos anos 70 do século $X X$, a palavra competência surge associada à qualificação profissional, vinculando-se ao posto de trabalho e associando-se ao colectivo, à organização. Nesta perspectiva empresarial, a competência é interpretada como uma forma de flexibilização laboral e de diminuição da precariedade do emprego.

Como defende Ceitil (2006), o termo competência tem sido perspectivado ora como atribuição, ora como qualificação, ora como traço/característica pessoal, ora como comportamento/acção, chamando a atenção ora para características extra-pessoais (perspectiva das atribuições e das qualificações), ora intra-pessoais (perspectiva dos traços/ características pessoais) e/ou comportamentais.

Em Educação o conceito de competência tem surgido como alternativa a capacidade, habilidade, aptidão, potencialidade, conhecimento ou savoir-faire. É a competência que permite ao sujeito aprendente enfrentar e regular adequadamente um conjunto de tarefas e de situações educativas.

Neste sentido, competência será um constructo teórico que se supõe como uma construção pessoal, singular, específica de cada um. É única e pertence, exclusivamente, à pessoa, exprimindo-se pela adequação de um indivíduo a uma situação. Não se visualiza, observam-se os seus efeitos (Rey, Carette, Defrance, \& Kahn, 2005).

Para Roldão (2003), a competência emerge quando, perante uma situação, o sujeito é capaz de mobilizar adequadamente diversos conhecimentos prévios, seleccioná-los e integrá-los de forma ajustada à situação em questão. Desta forma, a competência exige apropriação sólida e ampla de saberes, de modo a permitir ao sujeito que os convoque (de forma ajustada) quando se encontra face a diferentes situações e contextos. Competência recorre, desta forma, a noções, conhecimentos, informações, procedimentos, métodos e técnicas.

Cruz (2001) define competência como um conceito que acolhe saberes, atitudes e valores, abarcando o domínio do self (saber-ser), o domínio cognitivo (saber formalizado) e o domínio comportamental (saber-fazer) - a competência consolida-se numa acção ou no conjunto de acções organicamente articuladas. Este autor e Alves (2005), perspectivam a competência como a capacidade que as pessoas desenvolvem de articular, relacionar os diferentes saberes, conhecimentos, atitudes e valores; como uma acção cognitiva, afectiva, social que se torna visível em práticas e acções que se exercem sobre o conhecimento, sobre o outro e sobre a realidade. Constitui-se por um conjunto de saberes, de saberes-fazer e de atitudes que podem ser mobilizadas e traduzidas em performances. "A competência é agir com eficiência, utilizando propriedade, conhecimentos e valores na acção que desenvolve e agindo com a mesma propriedade em situações diversas" (Cruz, 2001, p. 31).

Como defende a União Europeia, a competência é uma combinação de conhecimentos, capacidades e atitudes adequadas ao contexto (Estella \& Vera, 2008).

Para Perrenoud (1999), uma competência traduz-se na capacidade de agir eficazmente perante um determinado tipo de situação, apoiada em conhecimentos, mas sem se limitar a eles. É um saber em uso que exige integração e mobilização de conhecimentos, processos e predisposições que, ao incorporarem-se uns nos outros, vão permitir ao sujeito fazer, pensar, apreciar (Roldão, 2002). Constitui a faculdade de mobilização de recursos cognitivos, com vista à resolução com pertinência e eficácia de uma série de situações (Gentille \& Bencini, 2000).

Nestas enunciações, podemos encontrar diferentes componentes das competências: saber-saber, saber-fazer, saber-ser. Definir competência através de cada uma destas componentes pode ser, no entanto, uma tentação perigosa, uma vez que (1) os saberes fazem parte da competência, mas não se podem confundir com ela; (2) as competências são descritas como acções, mas não é o facto de descrever as acções que explica ou que possibilita a acção ou o êxito; (3) as competências estão directamente relacionadas com o contexto e o saber ser não tem implícito esse contexto. 
Comparar competência a recursos, a uma adição de saberes, saberes-fazer e saberes-ser, apreendendo-a como um estado, é negligenciar a perspectiva de construção pessoal subjacente a este constructo - um indivíduo sábio não é necessariamente competente, nem a competência é um somatório, mas uma combinatória de elementos em que cada um se modifica em função das características daqueles aos quais se junta.

Juntar estas três componentes, numa adição de partes, levanta, desta forma, problemas conceptuais (Beaufils, 2006).

A competência integra e coordena um conjunto de esquemas (de percepção, pensamento, avaliação e acção) que sustém inferências, antecipações, transposições analógicas, generalizações, probabilidades, recolha de informação pertinente, tomada de decisão. A competência integra, assim, raciocínios, decisões conscientes, inferências, hesitações, ensaios e erros para se ir automatizando e constituindo-se num esquema complexo (Pereira, 2005). Como afirmam Perrenoud, Thurler, Macedo, Machado e Allessandrini (2002, p. 19) "(...) define-se competência como a aptidão para enfrentar uma família de situações análogas, mobilizando de uma forma correcta, rápida, pertinente e criativa, múltiplos recursos cognitivos: saberes, capacidades, micro competências, informações, valores, atitudes, esquemas de percepção, de avaliação e de raciocínio".

A competência apropria-se, assim, da acção, preexiste e exige recursos e meios para os mobilizar. Se não há recursos a mobilizar não há competência, e se há recursos mas não é possível mobilizá-los a tempo, é como se não existissem (Perrenoud, 2001, 2005; Pereira, 2005). Para que exista essa mobilização é necessário que o sujeito transfira conhecimentos, portanto, a mobilização inclui a transferência e acontece em situações complexas onde o sujeito pode estabelecer o problema antes de o resolver, determinar quais os conhecimentos essenciais a recorrer, como reorganizar os dados em função da situação (Pereira, 2005).

A noção de competência remete para situações nas quais é preciso tomar decisões e resolver problemas, associa-se à compreensão e avaliação de uma situação, uma mobilização de saberes, de modo a agir/reagir adequadamente. Desta forma, a tomada de decisão (expressar conflitos, oposições), a mobilização de recursos (afectivos e cognitivos) e o saber agir (saber dizer, saber fazer, saber explicar, saber compreender) são as características principiais da competência. Estas características permitem entender este conceito como uma forma de controlar (simbolicamente) as situações da vida.

Para Rychen e Tiana (2005), competência designa um sistema de acção complexo que envolve aptidões cognitivas e não cognitivas. Ser competente exige sistemas de acção complexos que abarcam conhecimentos, estratégias e rotinas necessárias para os aplicar, emoções e atitudes adequadas e auto-regulação. Definir a competência pela componente do que conseguimos fazer de forma sistemática, apela a processos de ordem cognitiva, a estratégias da resolução de problemas às quais um indivíduo recorre quando age.
Ser competente permite ao sujeito ser autónomo em relação ao uso do saber, possibilita-lhe activar recursos (conhecimentos, capacidades, estratégias) em diversos tipos de situações, nomeadamente, situações problemáticas. Ser competente será ser capaz de recorrer ao que se sabe para se realizar o que se deseja/projecta. O indivíduo competente será aquele que, num determinado domínio, enfrenta eficazmente uma situação inesperada, mobilizando e conjugando saberes, saberes-fazer e técnicas. Como defende Comellas (2000), uma pessoa será competente num determinado domínio se colocar em acção diferentes capacidades e saberes necessários para dar uma resposta ajustada à situação em que se encontra. Ao atingir a realização pessoal, ao exercer a cidadania activa, ao fomentar a inclusão social e o emprego, o sujeito manifesta as suas competências (Estella \& Vera, 2008).

Em síntese, a competência é uma combinação de conhecimentos, motivações, valores e ética, atitudes, emoções, bem como outras componentes de carácter social e comportamental que, em conjunto, podem ser mobilizadas para gerar uma acção eficaz num determinado contexto particular. Permite gerir situações complexas e instáveis que exigem recorrer ao distanciamento, à metacognição, à tomada de decisão, à resolução de problemas. Podemos, pois, afirmar que a competência se caracteriza por ser complexa, projectada no futuro (numa aposta nos poderes do tornar-se). Exerce-se em situação, é completa, consciente e transferível para outros contextos.

No âmbito educativo, solicita-se aos diferentes intervenientes (docentes e discentes) que mobilizem as suas aquisições (pessoais, sociais, académicas, ...) perante situações diversas, complexas e imprevisíveis. Solicita-se competência para fazer face aos desafios actuais (e futuros), numa alusão a uma conexão que combina recursos e acções do sujeito e traduz uma contribuição pessoal para um determinado desfecho. Solicita-se conhecimento em acção (Boterf, 2003). Defende-se que o sujeito é produtor e portador de competências, detentor de um conjunto de valores (como a colaboração, o empenho ou a mobilidade) que deverão ser tidos em conta na abordagem às competências (Boterf, 2003; Costa, 2004).

\section{Abordagem por competências: uma perspectiva educativa}

A partir das definições previamente apresentadas, podemos verificar que a emergência da noção de competência na área da Educação evidenciou mudanças epistemológicas. Nos anos 60 do século $X X$, o behaviorismo teve uma grande influência no desenvolvimento dos objectivos pedagógicos, identificando os comportamentos que deviam ser expressos pelos alunos e promovendo os níveis de desempenho considerados adequados e sujeitos a avaliação.

Nas últimas décadas, tem-se inflectido para uma perspectiva cognitivista e construtivista, sendo que o enfoque tem recaído na construção interna do sujeito, no poder e desejo que dispõe para desenvolver o que the pertence como actor autónomo da sua aprendizagem. Os objectivos pedagógicos passam a visar as competências a adquirir pe- 
los alunos ao longo do seu percurso académico. O processo de desenvolvimento e aprendizagem sublinha o progresso do conhecimento e da personalidade através da vivência de experiências significativas e de actividades pedagógicas cuidadosamente concebidas e planeadas.

O conceito de competência incorpora directrizes da escola activa e estende-se aos programas e currículos escolares, considerados instrumentos imprescindíveis para o desenvolvimento de sujeitos autónomos, capazes de enfrentar a mudança, de se adaptarem a novas situações e de funcionarem de forma activa como cidadãos. A noção de competência contribui para um novo significado de escola que já não se ajusta à trilogia do saber-fazer (ler, escrever e contar), a qual fundamentou a escolaridade obrigatória do século $X X$ (Rychen \& Tiana, 2005). Numa lógica de competências, a escola do século XXI, preocupa-se com a preparação de todos os alunos para a vida.

Uma abordagem ao ensino/aprendizagem por competências incita a considerar os saberes como recursos a serem mobilizados, a trabalhar por meio de problemas, a criar e/ou (re)utilizar novas metodologias de ensino/aprendizagem, a negociar e a desenvolver projectos com os alunos, a optar por uma planificação flexível, a incentivar o improviso, a caminhar no sentido de uma maior integração disciplinar, na direcção do desenvolvimento de um trabalho multidisciplinar.

Uma abordagem por competências muda os ofícios dos seus intervenientes, ou seja, muda o ministério do aluno e do professor. O estudante terá que se envolver, terá que se entusiasmar com as aprendizagens a realizar. $O$ docente, por sua vez, transforma-se num fiador de saberes, num organizador de aprendizagens, num incentivador de projectos, num gestor da heterogeneidade, num regulador de percursos formativos (Perrenoud, 2001, 2005).

A escola que sustenta a sua acção numa abordagem baseada nas competências defende a integração, pelo indivíduo, dos saberes (saberes teóricos e práticos), do saberfazer e das atitudes necessárias ao acompanhamento das tarefas. "(...) É, assim, justo ligar esta abordagem à corrente construtivista segundo a qual o conhecimento se constrói pela interacção do indivíduo com o seu meio" (Alves, 2005, p. 38). Construir é coordenar perspectivas na direcção que se pretende, num contexto que será sempre assombrado pela dúvida, pelo conflito, pela oposição.

Numa perspectiva construtivista, considera-se que o conhecimento se constrói progressivamente através da interacção entre o sujeito e o meio. O conhecimento não se adquire por uma interiorização de um determinado significado exterior dado, mas sim pela construção a partir de dentro de representações e interpretações adequadas, pelo que é importante encontrar sentido nos factos (estabelecer relações). Constrói-se através dos sentidos, que possibilitam a interacção com o ambiente e a edificação de uma imagem do mundo (Marujo \& Neto, 2004; Marujo, Neto, \& Perloiro, 2000).

A escola deve incentivar a acção dos alunos (captar, relacionar, integrar, conferir sentido, recriar informação), a tomada de iniciativa pessoal e o desenvolvimento da autoconfiança. Deve incentivar um ensino que tenha significado do ponto de vista do aluno, que o leve a encontrar as respostas às suas perguntas, através da experiência, raciocínios, críticas, confrontação de pontos de vista.

A escola que defende uma perspectiva construtivista parte dos conhecimentos prévios dos alunos e leva-os a construir o seu conhecimento, a encontrar valores morais, seja através da criação de oportunidades de trocas de pontos de vista ou da expressão de opiniões. Considera o sujeito aprendente, os seus objectivos e possibilidades de aprendizagem, utilizando o conflito cognitivo e sócio-cognitivo, a descoberta, a procura, a curiosidade, a pesquisa, como formas de aprendizagem e de construção de regras. Gera sentimentos de competência, promovendo auto-imagens positivas.

Esta escola centra a atenção no sujeito, incentivandoo a encontrar informação por si mesmo. Fomenta o aprender a aprender, desenvolve a capacidade dos sujeitos para realizarem aprendizagens significativas por si mesmos, num vasto conjunto de situações e circunstâncias. Valoriza a aquisição de estratégias cognitivas de exploração e de descoberta, de planificação e de regulação da própria actividade. Incentiva a formulação de hipóteses, de experimentar e de raciocinar sobre dados e sobre o sentido das coisas. Fomenta o aprender a pensar, a "(...) focalizar a atenção nos problemas, na forma de colocar questões e no processo de resolução dos mesmos, mais do que oferecer directamente as soluções" (Rosário, 1997, p. 239), valorizando o processo, a auto-reflexão, o controlo pessoal e a consciencialização do próprio processo.

A meta principal da escola de hoje não é, assim, ensinar conteúdos, mas desenvolver competências que permitam ao sujeito alcançar sucesso pessoal e profissional. Visa permitir a cada um aprender a utilizar os seus saberes para actuar com eficiência. Esta escola fomenta o carácter adaptativo e converte os conteúdos em meios que possibilitam aos alunos desenvolver competências - a pedagogia do aprender a aprender elege-se como fundamento e posicionamento valorativo: valorização do método, em detrimento do conteúdo; do processo de aprendizagem, em prejuízo da transmissão de conhecimentos; do aluno como protagonista do seu processo de aprendizagem, em perda do professor como figura central desse processo; da rápida absorvência dos conteúdos nesta suposta sociedade de informação, na qual as mudanças são cada vez mais rápidas, exigindo constante actualização e adaptação dos indivíduos (Costa, 2004).

Num processo educativo centrado na aprendizagem e no sujeito aprendente (e nas suas capacidades para aprender), torna-se evidente uma abordagem por competências (González \& Wagenaar, 2003). Como defendem Estella e Vera (2008, p. 171), "enfocar la ensenãnza (...) buscando la formación en competencias, implica un aprendizaje activo que presupone la motivación para aprender, la capacidad para emitir un juicio crítico y la facultad para saber cómo aprender".

Nesta perspectiva construtivista, a aprendizagem é uma procura permanente do significado das coisas, pelo que se deve apoiar em conceitos estruturais e primários que possibilitem a interligação entre eles. Aprender significa construir significados. Neste processo, a interacção com os outros ori- 
gina perturbações, exige reflexões conjuntas que, ao serem resolvidas, gera adaptação e sentido ao aprendido (Marujo \& Neto, 2004). "A discussão em grupo ajuda os alunos a identificarem lacunas nos seus conhecimentos e a entenderem como a nova informação se relaciona com conceitos mais amplos e inclusivos" (Almeida, 2002, p. 160).

Nesta óptica activa e cooperativa ensinar será conceber, encaixar e regular situações de aprendizagem, propor tarefas complexas e desafios que incitem (todos) os alunos a mobilizar os seus conhecimentos e, em certa medida, a completá-los.

Como defende Freire (2004, p. 22), “(...) ensinar não é transferir conhecimento, mas criar as possibilidades para a sua produção ou a sua construção".

A abordagem por competências equaciona a diferenciação pedagógica como a metodologia de trabalho a utilizar, valorizando o diálogo entre docente(s) e discente(s).

Para Visser (1993), a diferenciação pedagógica contempla o desafio de fazer progredir no currículo uma criança em situação de grupo, através da selecção apropriada de ensino e estratégias de aprendizagem e estudo. Desta forma, assume-se a heterogeneidade como um recurso fundamental da aprendizagem, adoptando-se a colaboração dos sujeitos, a aprendizagem cooperativa, como recurso para regular a aprendizagem e individualizar percursos educativos.

Ao organizar-se as actividades e as interacções de modo a que cada aluno seja frequentemente confrontado com situações pedagógicas significativas para si e adequadas às suas características, está a procurar dar-se uma resposta a todos os alunos, o que fomentará o sucesso educativo (Grave-Resendes \& Soares, 2002).

Criar situações pedagógicas geradoras de sentido e de aprendizagem, diferenciá-las para que cada aluno seja requerido na sua zona de desenvolvimento próximo, optar por uma observação formativa e por uma regulação da aprendizagem interactiva, considerar os efeitos das relações interpessoais e individualizar percursos formativos, são apenas algumas estratégias que podem ser adoptadas numa lógica de trabalho por problemas e/ou por projectos.

Numa perspectiva sócio-construtivista, o desenvolvimento inicia-se no plano social, na relação com os outros. O sujeito realiza algo com alguém e é precisamente essa experiência de partilha com o outro que possibilita a interiorização das principais funções cognitivas - o sujeito aprende com os outros para, mais tarde, saber fazer sozinho. Neste processo, a linguagem é essencial, servindo como mediadora entre o nível de funcionamento inter-psicológico - nível social - e o nível de funcionamento intra-psicológico - nível individual (Almeida, 2002; Raposo, Bidarra, \& Festas, 1998; Vygotsky, 1991).

Com os outros (alunos, colegas e outros intervenientes educativos), por meio da exploração, da conversa, da partilha, de uma atmosfera de liberdade, constroem-se conhecimentos e afectos que permitem o desenvolvimento harmonioso do sujeito.

Porque não há docência sem discência (Freire, 2004), uma abordagem do ensino/aprendizagem por competências contribuirá para (1) aumentar o significado do trabalho académico e modificar a relação com o saber dos alunos em dificuldade; (2) facilitar a assimilação activa de saberes aproximando construtivismo e pedagogia diferenciada; (3) colocar os professores em movimento, incitando-os a falar de pedagogia e a cooperar no quadro de equipas ou de projectos de estabelecimento escolar. Concorrerá para fomentar a relação com a vida profissional, o desenvolvimento pessoal dos estudantes, ajudando-os a assumir responsabilidades sociais, a resolver problemas e a adaptar-se às mudanças sociais (González \& Wagenaar, 2003).

\section{Considerações finais}

Em situação de ensino/aprendizagem, o indivíduo aprende a identificar e a descobrir conhecimentos, a mobilizálos de forma contextualizada. Ser competente não é realizar uma mera assimilação de conhecimentos suplementares, gerais ou locais, mas sim, compreende a construção de esquemas que permitem mobilizar conhecimentos na situação certa e com discernimento. A partir da formação de uma decisão ou procura de informação pertinentes, estes esquemas de percepção, pensamento, avaliação e acção suportam interferências, antecipações, generalizações e apreciações de probabilidades. Ao construir competências considera-se o contexto de aprendizagem, a implicação do sujeito na tomada de decisão, a resolução de situações problemáticas e o próprio processo de construção de conhecimento.

Uma abordagem por competências defende que o sujeito constrói os seus próprios saberes, numa interacção afectiva que possibilita o aprender a aprender.

Em contexto educativo, com os outros, o sujeito (re)descobre, (re)inventa novas possibilidades de acção que the permitem situar-se critica e autonomamente na sociedade actual.

\section{Referências}

Almeida, L. S. (2002). Facilitar a aprendizagem: ajudar aos alunos a aprender e a pensar. Psicologia Escolar e Educacional, 6(2), 155165.

Alves, P. (2005). Dos objectivos às competências: implicações para a avaliação de um programa de formação de professores. Em J. C. Morgado \& M. P. Alves (Orgs.), Mudanças educativas e curriculares ... e os educadores/professores? Actas do Colóquio sobre Formação de professores (pp. 29-42). Braga: Universidade do Minho: Centro de Investigação em Educação - Departamento de Currículo e Tecnologia Educativa.

Beaufils, A. (2006). Um painel de bordo para a avaliação da formação. Em J. Tavares, A. Pereira, C. Fernandes \& S. Monteiro (Orgs.), Activação do desenvolvimento psicológico - Actas do Simpósio Internacional (pp. 97-104). Aveiro, Portugal: Universidade de Aveiro.

Boterf, G. (2003). Desenvolvendo as competências profissionais. Porto Alegre: Artmed. 
Ceitil, M. (Org.). (2006). Gestão e desenvolvimento de competências. Lisboa: Edições Sílabo.

Comellas, M. (2000). La formación competencial del profesorado: formación continuada y nuevos retos organizativos. Educar, 27, 87-101.

Costa, A. (2004). Quatro questões sobre a noção de competências na formação de professores: o caso brasileiro. Revista de Educação. 12(2), 95-106.

Cruz, C. (2001). Competências e habilidades: da proposta à prática. São Paulo: Edições Loyola.

Dolz, J., \& Ollagnier, E. (2004). O enigma da competência em educação. Porto Alegre: Artmed Editora.

Estella, A. M., \& Vera, C. S. (2008). La ensenãnza en competências en el marco de la educación a lo largo de la vida y la sociedad del conocimiento. Revista IberoAmericana de Educación, 47, 159-183.

Freire, P. (2004). Pedagogia da autonomia. Saberes necessários à prática educativa. São Paulo: Editora Paz e Terra.

Gentille, P., \& Bencini, R. (2000). Construindo competências Entrevista com Philippe Perrenoud. Recuperado: 28 fev. 2002. Disponível: http://www.unige.ch/fapse/SSE/teachers/perrenoud/ php_main/php_2000/2000_31.html

González, J., \& Wagenaar, R. (Eds.). (2003). Tuning Educational Structures in Europe. Informe final. Fase Uno. Deusto, Espanha: Universidade de Deusto e Universidade de Groningen.

Gouveia, J. (2007). Competências: moda ou inevitabilidade?. Saber (e) Educar, 12, 31-58.

Grave-Resendes, L., \& Soares, J. (2002). Diferenciação pedagógica. Lisboa: Universidade Aberta.

Marujo, H., \& Neto, L. (2004). Optimismo e esperança na educação. Lisboa: Editorial Presença.

Marujo, H., Neto, L., \& Perloiro, M. (2000). Educar para o optimismo. Lisboa: Editorial Presença.

Pereira, M. (2005). O currículo por competências - a construção de um instrumento de verificação do desenvolvimento das

\section{Sobre a autora}

Isabel Simões Dias (mdias@esecs.ipleiria.pt) Instituto Politécnico de Leiria da Escola Superior de Educação e Ciências Sociais, Leiria - Portugal aprendizagens, mediador da cooperação entre professores e psicólogos da educação. Revista do Movimento da Escola Moderna, 23, 5-43.

Perrenoud, P. (1999). Construir as competências desde a escola. Porto Alegre: Artmed Editora.

Perrenoud, P. (2000). Dez novas competências para ensinar. Porto Alegre: Artmed Editora.

Perrenoud, P. (2001). Porquê construir competências a partir da escola? Porto: Edições Asa.

Perrenoud, P. (2005). Escola e cidadania. O papel da escola na formação para a democracia. Porto Alegre: Artmed Editora.

Perrenoud, P., Thurler, M., Macedo, L., Machado, N., \& Allessandrini, C. (2002). As competências para ensinar no século XXI. A formação dos professores e o desafio da avaliação. Porto Alegre: Artmed Editora.

Raposo, N., Bidarra, M., \& Festas, M. (1998). Dificuldades de desenvolvimento e aprendizagem. Lisboa: Universidade Aberta.

Rey, B., Carette, V., Defrance, A., \& Kahn, S. (2005). As competências na escola. Aprendizagem e avaliação. Vila Nova de Gaia, Portugal: Gailivro.

Rychen, D., \& Tiana, A. (2005). Desenvolver competências - chave em educação. Algumas lições extraídas da experiência nacional $e$ internacional. Porto: Edições Asa.

Roldão, M. (2002). De que falamos quando falamos de competências? Noesis. Janeiro/Março, 59- 62.

Roldão, M. (2003). Gestão do currículo e avaliação de competências - as questões dos professores. Lisboa: Editorial Presença.

Rosário, P. (1997). Facilitar a aprendizagem através do ensinar a pensar. Psicopedagogia, Educação e Cultura, 1(2), 237-249.

Visser, J. (1993). Differentiation: making it work: ideas for the staff development. Stafford: Nasen.

Vygotsky, L. S. (1991). Pensamento e linguagem. São Paulo: Martins Fontes.

Recebido em: 23/06/2009 Reformulado em: 05/07/2010 Aprovado em: 08/07/2010

\section{Correspondência}

Isabel Simões Dias

Rua Dr. João Soares

Apartado 4045

2411-901 Leiria - Portugal 